\title{
Preparation and Mechanical Properties of Ceramic Fiber Reinforced Titanium-Based Hybrid Laminated Composite
}

\author{
Guoqing Zhang $\mathbb{D}^{1,2}$ Shuxia Li, ${ }^{3}$ Haitao Qu, ${ }^{3}$ Hongliang Hou, ${ }^{3}$ Bing Zhao, ${ }^{3}$ \\ Zhigang Wang $\mathbb{D}^{4}{ }^{4}$ Hongtao Zhang $\mathbb{D}^{2},{ }^{2}$ and Yunlong Zhang $\mathbb{D}^{2}$ \\ ${ }^{1}$ The College of Mechatronic Engineering, North University of China, Taiyuan 030051, China \\ ${ }^{2}$ Flight College, Anyang Institute of Technology, Anyang 455000, China \\ ${ }^{3}$ Metal Forming Technology Department, AVIC Manufacturing Technology Institute, Beijing 100024, China \\ ${ }^{4}$ The College of Mechanical Engineering, Anyang Institute of Technology, Anyang 455000, China
}

Correspondence should be addressed to Guoqing Zhang; zgq4111@sina.com

Received 6 November 2021; Revised 17 December 2021; Accepted 3 January 2022; Published 24 January 2022

Academic Editor: V. Vijayan

Copyright (c) 2022 Guoqing Zhang et al. This is an open access article distributed under the Creative Commons Attribution License, which permits unrestricted use, distribution, and reproduction in any medium, provided the original work is properly cited.

\begin{abstract}
Based on traditional titanium-based composites and the design concept of biomimetic laminated structures, the continuous $\mathrm{SiC}$ ceramic fiber, ductile metal $\mathrm{Ti}$ foil, and intermetallic $\mathrm{Ti}_{2} \mathrm{AlNb}$ foil were selected as structural components, which were alternately stacked in the sequence of $\mathrm{Ti}_{2} \mathrm{AlNb}-\mathrm{Ti}-\mathrm{SiC}_{f}-\mathrm{Ti}^{-} \mathrm{Ti}_{2} \mathrm{AlNb}$ to prepare the continuous $\mathrm{SiC}$ ceramic fiber-reinforced titanium-based laminated composite. The methods adopted were vacuum hot-pressing and ceramic fiber braiding. In the prepared state, the composite's structural components were metallurgically bonded ideally, and the continuous SiC ceramic fiber was equidistantly distributed in the ductile metal Ti matrix. This composite's phase is mainly composed of $\alpha$ - Ti, $\beta$-Ti, $\mathrm{SiC}, \mathrm{TiC}, \mathrm{O}$, and $\mathrm{B} 2 \mathrm{phases}$. In addition, along the ceramic SiC fiber lengthwise, the tensile test was performed on this composite at room temperature and a high temperature of $600^{\circ} \mathrm{C}$, with the ultimate tensile strength being $948.76 \mathrm{MPa}$ and $526.62 \mathrm{MPa}$, respectively, and, in this process, the fiber was debonded and pulled out. Meanwhile, the composite's bending strength was measured to be $1506.21 \mathrm{MPa}$ in a threepoint bending test, and, under this bending load, the mode of crack propagation and failure mechanism were analyzed.
\end{abstract}

\section{Introduction}

The continuous $\mathrm{SiC}$ ceramic fiber-reinforced titanium-based composite has a great potential to be used as the structural material in the aerospace industry because it has excellent mechanical properties, such as high specific strength and stiffness, as well as good fatigue resistance [1-4]. Generally, the matrix alloy of traditional $\mathrm{SiC}_{f} / \mathrm{Ti}$ composites refers to disordered titanium alloys, such as TC4 and TC17. In recent years, scientific researchers have been developing titaniumbased composites based on ordered Ti-Al intermetallic compounds, such as $\mathrm{TiAl}, \mathrm{Ti}_{2} \mathrm{AlNb}$, and $\mathrm{Ti}_{3} \mathrm{Al}$. Compared with typical disordered titanium alloys, these Ti-Al intermetallic alloys have better high-temperature performance and higher environmental stability [5-9].

However, certain inherent defects exist in these Ti-Al intermetallic compounds, including low room-temperature plasticity, low ductility, poor fracture resistance, and poor damage tolerance. In view of this, the damage tolerance and mechanical properties of titanium-based composites need to be further improved to meet the requirements of structural design. Being inspired by natural creatures in design, researchers have found that the internal hierarchical structure of shells endows them with excellent fracture resistance, toughness, and damage tolerance $[4,10-12]$. The nacre and special protein layer of shells are alternately laminated to 
form a ductile-brittle combination. As a result, when shells are subjected to an external load, the crack propagation will be deflected due to the stepped hierarchical structure, and the crack path will be extended to form an effective toughening mechanism [13-17].

Therefore, the design concept of this ductile-brittle laminated structure can provide inspiration for advanced structural materials that are produced to meet certain performance requirements. Using the hot charge rolling technology, Sun et al. [18] prepared the metal-intermetallic laminated composite alternately stacked with high-temperature titanium alloys and Ti-43Al-9V. This composite is of good mechanical properties, especially in fracture toughness. The ductile-brittle laminated structure will contribute to the crack deflection and tip passivation under the load, which greatly improves the toughness of this composite. Lyu et al. [19] selected $\mathrm{Ti}$ and $\mathrm{Al}$ foils as raw materials to prepare the $\mathrm{Ti} /$ TiAl intermetallic laminated plate by vacuum hot pressing. This plate's microstructure shows that the ductile metal Ti and brittle intermetallic compound TiAl are alternately laminated, and the plate's fracture toughness is evidently better than that of the single TiAl.

Based on the analysis above, the traditional continuous $\mathrm{SiC}$ ceramic fiber-reinforced titanium-based composite was selected as the design prototype in this paper to integrate with the concept of biomimetic laminated structures in shells. In other words, with the continuous $\mathrm{SiC}$ ceramic fiber as reinforcement, the disordered ductile titanium alloy (TA2 foil) and ordered brittle $\mathrm{Ti}-\mathrm{Al}$ intermetallic compound $\left(\mathrm{Ti}_{2} \mathrm{AlNb}\right.$ foil) were alternately stacked in the sequence of $\mathrm{Ti}_{2} \mathrm{AlNb}-\mathrm{TA} 2-\mathrm{SiC}$ ceramic fiber-TA2- $\mathrm{Ti}_{2} \mathrm{AlNb}$ to form a composite with the hybrid matrix. In the meantime, the continuous $\mathrm{SiC}$ ceramic fiber-reinforced titanium-based laminated composite was prepared by vacuum hot-pressing and ceramic fiber braiding. By laminating this hybrid matrix, the composite was designed to combine the high strength and stiffness of the intermetallic compound $\mathrm{Ti}_{2} \mathrm{AlNb}$, the high toughness and ductility of the ductile metal $\mathrm{Ti}$, and the high strength of the $\mathrm{SiC}$ ceramic fiber, which provided a reference for the structural design of new composites.

\section{Experimental Procedures}

2.1. Design and Preparation of the Composite. The continuous $\mathrm{SiC}$ ceramic fiber used for this experiment was composed of the $\beta$-SiC with a hexagonal close-packed structure in the diameter of $0.1 \mathrm{~mm}$, and the fiber was sprayed with $2 \mu \mathrm{m} \mathrm{C}$ coating material. The pure industrial titanium foil was used in the ductile metal matrix layer, with the label of TA2, the purity of $99.80 \%$, and the thickness of $0.1 \mathrm{~mm}$. The $\mathrm{Ti}_{2} \mathrm{AlNb}$ foil was used in the intermetallic layer, with a thickness of $0.1 \mathrm{~mm}$ and the nominal composition of Ti-22Al-25Nb (at \%).

Figure 1 is the schematic diagram for the hot-pressing preparation of the continuous $\mathrm{SiC}$ ceramic fiber-reinforced titanium-based laminated composite. In this experiment, the metal $\mathrm{Ti}$ foil and intermetallic $\mathrm{Ti}_{2} \mathrm{AlNb}$ foil were cut into rectangles in the size of $40 \mathrm{~mm} \times 60 \mathrm{~mm}$ by foil scissors. Meanwhile, these foils were polished on upper and lower surfaces with abrasive paper of different particle sizes to remove the oxidation film and other impurities. Then, the foils were washed by a high-power ultrasonic wave in the acetone solution for $20 \mathrm{~min}$ to mechanically remove the impurities attached to the upper and lower surfaces due to polishing so that these foils were clean enough for the experiment. After that, they were dried in vacuum conditions. In order to enable the ceramic SiC fiber uniformly and equidistantly arranged in the TA2 matrix of the hybrid laminated composite, the continuous ceramic SiC fiber was braided and distributed uniformly in a programmable fiber winding machine. In this process, the axial distance between monofilaments was $200 \mu \mathrm{m}$, and the braiding width of the $\mathrm{SiC}$ ceramic fiber cloth was $40 \mathrm{~mm}$. Then, the powdered polymethyl methacrylate (PMMA) was dissolved in the acetone solution and stirred with a glass rod to make it evenly mixed. After that, the uniformly mixed peptizing agent was sprayed onto the surface of the $\mathrm{SiC}$ ceramic fiber cloth through compressed air and the cloth was kept for 20 minutes. Afterward, the agent sprayed evaporates, and the surface of the $\mathrm{SiC}$ ceramic fiber cloth is further consolidated.

Next, the prepared Ti foil, $\mathrm{Ti}_{2} \mathrm{AlNb}$ foil, and $\mathrm{SiC}$ ceramic fiber cloth were alternately laminated with the structural components sequence of $\mathrm{Ti}_{2} \mathrm{AlNb}$ foil-Ti foil-SiC ceramic fiber cloth-Ti foil- $\mathrm{Ti}_{2} \mathrm{AlNb}$ foil, as shown in Figure 1. Among them, the fiber cloth was placed in the middle and covered with the metal Ti foil on the upper and lower surfaces and the intermetallic $\mathrm{Ti}_{2} \mathrm{AlNb}$ foil in the outermost layer, which formed a "sandwich" structure that was laminated repeatedly to prefabricate the composite. After this step, the stainless-steel fiber with a diameter of $100 \mu \mathrm{m}$ was used to bind and fix this prefabricated composite, which was later put into the vacuum hot-pressing sintering furnace, with the vacuum degree being $10^{-3} \mathrm{~Pa}$ and the accuracy of temperature control being $\pm 5^{\circ} \mathrm{C}$. The hot-pressing curve is presented in Figure 2.

In the process of hot-pressing sintering, the laminated composite went through three stages of hot working: Q1, in which the peptizing agent was removed from the $\mathrm{SiC}$ ceramic fiber cloth; Q2, in which the composite's structural components were metallurgically bonded by hot pressing; and Q3, in which the composite was cooled along with the furnace.

In Q1, the temperature in the hot-pressing furnace increased to $400^{\circ} \mathrm{C}$ at the rate of $3^{\circ} \mathrm{C} / \mathrm{min}$ and kept for $2 \mathrm{~h}$. With this temperature variation, the PMMA peptizing agent sprayed onto the fiber cloth started to volatilize gradually, which destroyed the external adhesion between monofilaments. Meanwhile, an external unidirectional vertical mechanical load of $5 \mathrm{MPa}$ between the upper and the lower pressure heads of the furnace was applied onto the prefabricated composite to fix the $\mathrm{SiC}$ ceramic fiber's geometric position. In Q2, the temperature in the furnace rose to a value preset for the hot working of this composite at the rate of $10^{\circ} \mathrm{C} / \mathrm{min}$. Then, the unidirectional vertical load between the upper and the lower pressure heads was increased to a preset pressure state through the hydraulic pump so that the composite's structural components were metallurgically bonded in a state of solid phase under high temperatures and 


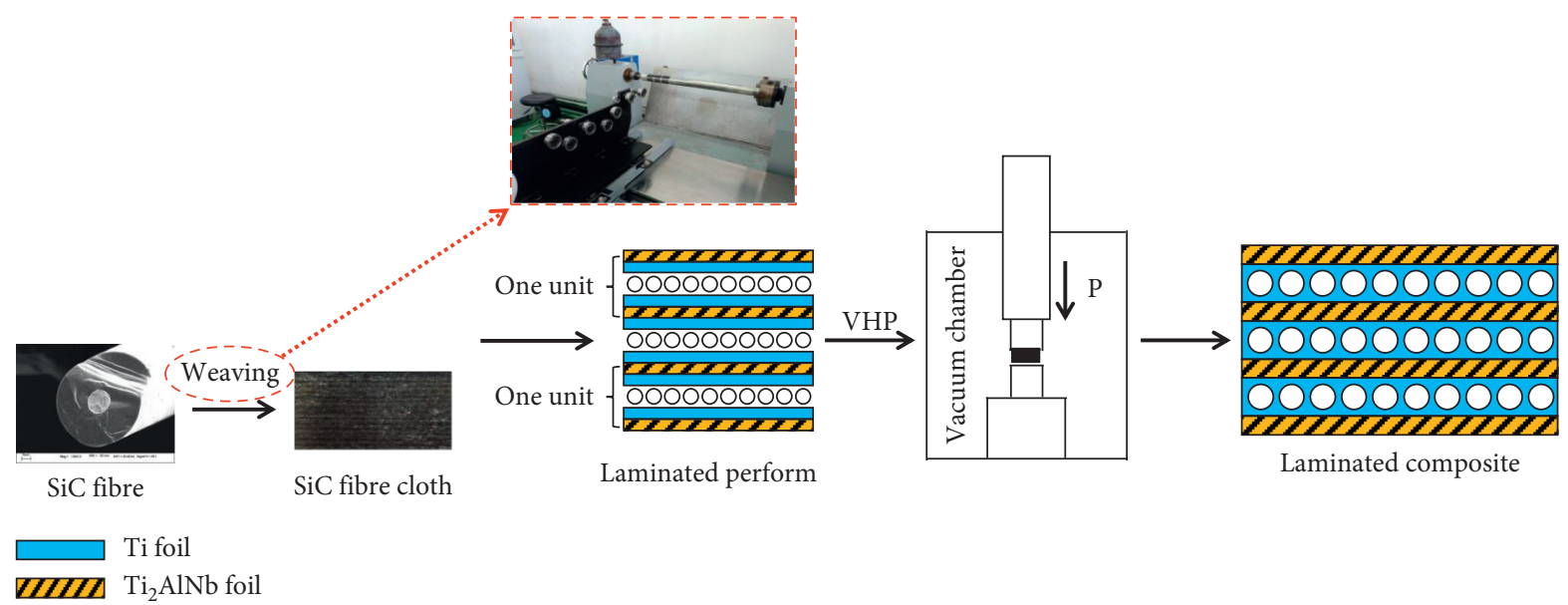

FIgURE 1: Schematic diagram for the hot-pressing fabrication of the composite.

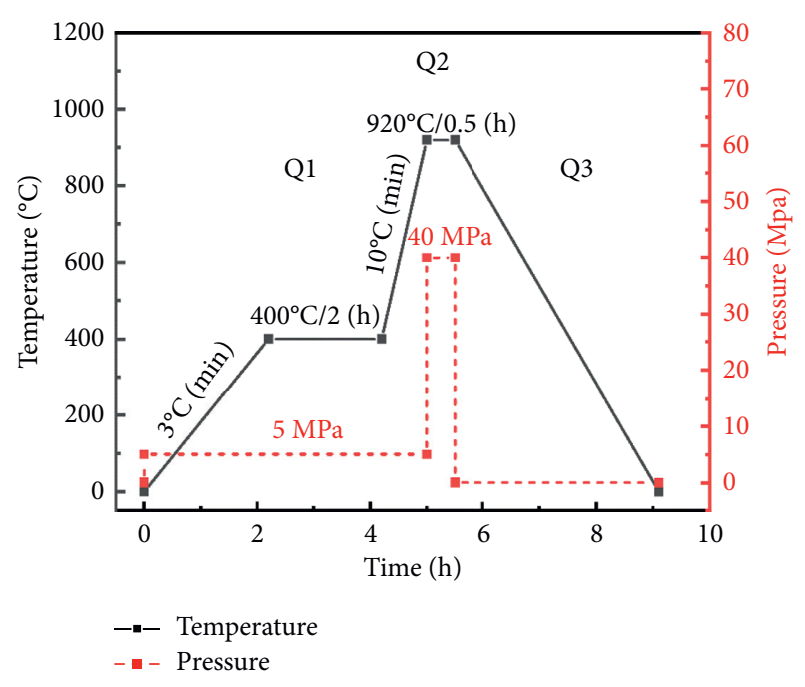

FIGURE 2: Hot-pressing curves of the composite.

pressures. In Q3, the composite was cooled along with the furnace to room temperature, bearing no external unidirectional vertical mechanical load.

2.2. Microstructural Characterization of the Composite. After the vacuum hot-pressing sintering, the prepared composite sample was cut perpendicularly along the axial direction of the $\mathrm{SiC}$ ceramic fiber by wire electrical discharge machining. Then, the cut sample was inlaid, ground, and polished. The scanning electron microscope (SEM) and its ancillary energy dispersive spectrometer (EDS) were used to analyze this sample's microstructure and element composition and distribution. Meanwhile, the composite's phase was identified with an X-ray diffractometer (XRD). In this process, the scanned area was $10^{\circ} \sim 100^{\circ}$; the step width was $0.02^{\circ}$; the scanning speed was $10^{\circ} / \mathrm{min}$; the Cu target was $\mathrm{K} \alpha$; and the interbank flow was $20 \mathrm{~mA}$.

2.3. Test on Mechanical Properties of the Composite. The laminated composite's tensile mechanical properties were tested at room and high temperatures along the axial direction of the $\mathrm{SiC}$ ceramic fiber to further evaluate these properties. In this tensile test, the composite sample was cut into the geometric size of $30 \mathrm{~mm} \times 5 \mathrm{~mm} \times 3 \mathrm{~mm}$, as shown in Figure 3(a). The test was performed on an electronic universal testing machine with a mechanical-hydraulic servo system, with the tensile strain rate set at $0.5 \mathrm{~mm} / \mathrm{min}$. To test the tensile mechanical properties at high temperatures, the resistance furnace attached to this electronic universal testing machine was heated to the test temperature of $600^{\circ} \mathrm{C}$ to mount the sample. After this temperature became constant, the sample was kept in the furnace for $5 \mathrm{~min}$ and then stretched to be broken completely.

The three-point bending test was carried out to obtain the composite's bending strength, with the loading process shown in Figure 3(b). In this test, the sample's geometric size was $35 \mathrm{~mm} \times 2 \mathrm{~mm} \times 2 \mathrm{~mm}$; the span between supporting points was $20 \mathrm{~mm}$; and the constant displacement loading rate was $0.5 \mathrm{~mm} / \mathrm{min}$. The composite's bending strength was calculated with the following equation:

$$
\sigma_{f}=\frac{3 F_{\max } L}{2 B W^{2}}
$$

where $\sigma_{f}$ denotes the composite's bending strength, $F_{\max }$ denotes the sample's maximum load in the test, $L$ denotes the span between supporting points, and $B$ and $W$ represent the sample's thickness and width, respectively.

\section{Results and Discussion}

3.1. Phase and Microstructure Analysis of the Composite. Figure 4 shows the XRD spectrum of the continuous $\mathrm{SiC}$ ceramic fiber-reinforced titanium-based laminated composite. It can be seen that this composite's phase is mainly composed of $\alpha$-Ti, $\beta$-Ti, $\mathrm{SiC}, \mathrm{TiC}, \mathrm{O}$ phase, and $\mathrm{B} 2$ phase in the prepared state.

Figure 5 presents the composite's microstructure in the prepared state. As shown in Figure 5(a), it is a laminated structure alternately stacked with $\mathrm{SiC}_{f} / \mathrm{Ti}$ and $\mathrm{Ti}_{2} \mathrm{AlNb}$ layers. Thereinto, the flat region marked by the red dotted line is the macroscopic linear morphology of the interface between the two layers, which shows that the metal $\mathrm{Ti}$ foil and the 


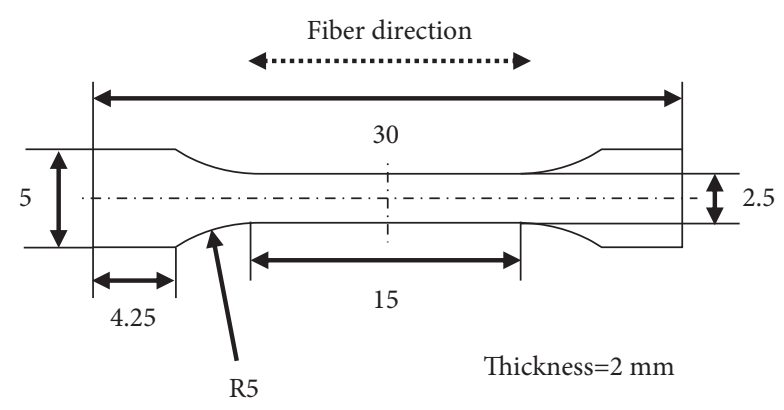

(a)

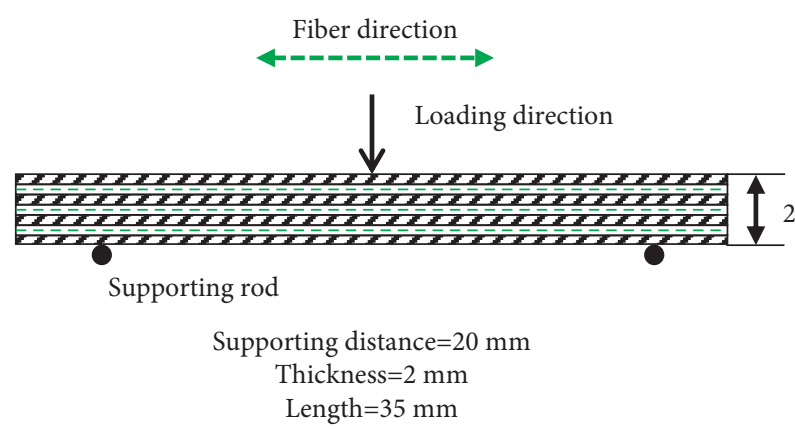

(b)

Figure 3: Dimensional drawing of the sample in mechanical properties testing: (a) size of the tensile sample and (b) size of the three-point bending sample.

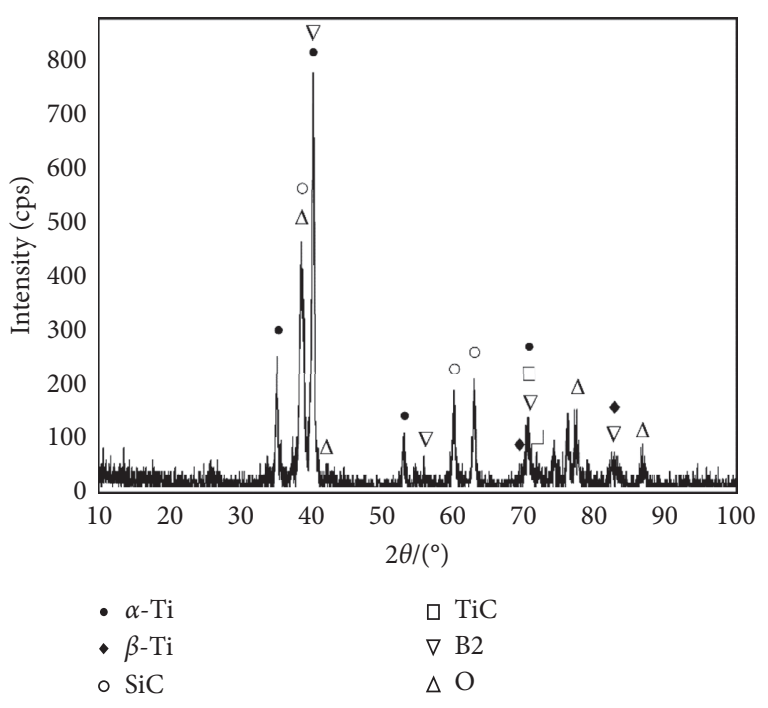

FIGURE 4: XRD spectrum of the composite.

intermetallic $\mathrm{Ti}_{2} \mathrm{AlNb}$ foil are metallurgically bonded well. In the $\mathrm{SiC}_{f} / \mathrm{Ti}$ layer, the $\mathrm{SiC}$ ceramic fiber is uniformly distributed in the "centerline" of the ductile metal Ti matrix. This indicates that, in the process of hot working, the SiC ceramic fiber cloth located in the middle of the composite's structural components has no geometric displacements in the direction of pressure under the external unidirectional vertical load. Instead, there is always a horizontal linkage between the monofilaments of this cloth during the hot forming process, which does not result in the irregular curve distribution of them in the ductile metal Ti layer. Besides, the distances $l_{1}, l_{2}$, and $l_{3}$ between them are measured to be $203 \mu \mathrm{m}, 206 \mu \mathrm{m}$, and $201 \mu \mathrm{m}$, respectively, by geometric parameter measurement in the $\mathrm{SiC}_{f} / \mathrm{Ti}$ layer, with an average value of $203.3 \mu \mathrm{m}$, which is approximate to $200 \mu \mathrm{m}$, a value preset for the axial distance between mechanically twined monofilaments of the $\mathrm{SiC}$ ceramic fiber cloth. This indicates that, during the hot working of the composite, the monofilaments of this cloth are directly "inlaid" into the ductile metal Ti matrix, without significant horizontal displacements under the external unidirectional vertical load. Thus, the $\mathrm{SiC}$ ceramic fiber can be distributed equidistantly and periodically in a certain direction in the composite's structural components.
Figure 5(b) enlarges the microstructure of each component in $\mathrm{SiC}_{f} / \mathrm{Ti}$ and $\mathrm{Ti}_{2} \mathrm{AlNb}$ layers of this laminated composite. It can be clearly observed that the ductile metal $\mathrm{Ti}$ matrix is fully filled in the spacing between $\mathrm{SiC}$ ceramic fibers to "wrap" them completely. In addition, the matrix and the fiber are combined smoothly, showing a natural transition at their interface with no "auriform" holes. Meanwhile, the ductile metal Ti and intermetallic compound $\mathrm{Ti}_{2} \mathrm{AlNb}$ are metallurgically bonded in a state of solid phase due to the interdiffusion of chemical elements. There are no holes or unclosed geometric defects at their interface, showing a good metallurgical bonding state.

Figure 5(c) is an interface diagram for the microstructure of $\mathrm{SiC}_{f} / \mathrm{Ti}$ at high magnification. It can be seen that, in the prepared state, there is a $\mathrm{C}$ coating in the thickness of about $1 \mu \mathrm{m}$ between the $\mathrm{SiC}$ ceramic fiber and the ductile metal $\mathrm{Ti}$, and the reaction layer at their interface is about $0.8 \mu \mathrm{m}$ thick. In the meantime, the EDS line scanning is carried out in the path from "a" to "b" to analyze the $\mathrm{SiC}_{f} / \mathrm{Ti}$ interface, with the results shown in Figure 5(d). According to this figure, the $\mathrm{Si}$ content gradually reduces while the Ti content gradually increases in the direction from $\mathrm{SiC}$ ceramic fiber to ductile metal Ti matrix. At the same time, the $\mathrm{C}$ content first increases and then decreases, showing a parabolic distribution; and it reaches the peak in the area near the point of intersection between $\mathrm{Si}$ and Ti distribution curves, showing the highest value. During the hot working of the composite, the $\mathrm{C}$ coating covering the $\mathrm{SiC}$ ceramic fiber contacts the ductile metal Ti matrix. Thus, the $\mathrm{Ti}$ and $\mathrm{C}$ atoms react with each other to generate $\mathrm{TiC}$, a brittle interfacial product $[20,21]$.

Figure 5(e) is an interface diagram for the microstructure of $\mathrm{Ti} / \mathrm{Ti}_{2} \mathrm{AlNb}$ at high magnification. It can be observed that there are two transition regions with different morphological structures at the interface between the ductile metal Ti layer and the intermetallic $\mathrm{Ti}_{2} \mathrm{AlNb}$ layer, as shown by Regions 2 and 3 in Figure 5(e). In Region 2 on the side of the ductile metal Ti layer, the microstructures of $\alpha+\beta$ biphase in the shape of needles or slats of different sizes are interlaced irregularly and distributed geometrically. In Region 3 on the side of the intermetallic $\mathrm{Ti}_{2} \mathrm{AlNb}$ layer, the microstructures of $\mathrm{O}$ phase in the shape of long or short slats are inlaid in the B2 phase of the $\mathrm{Ti}_{2} \mathrm{AlNb}$ matrix. Meanwhile, the EDS line scanning is carried out in the path from " $c$ " to " $\mathrm{d}$ " to analyze 


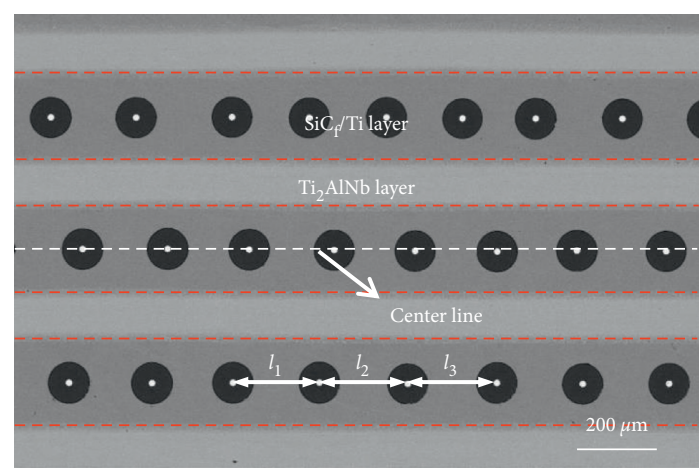

(a)

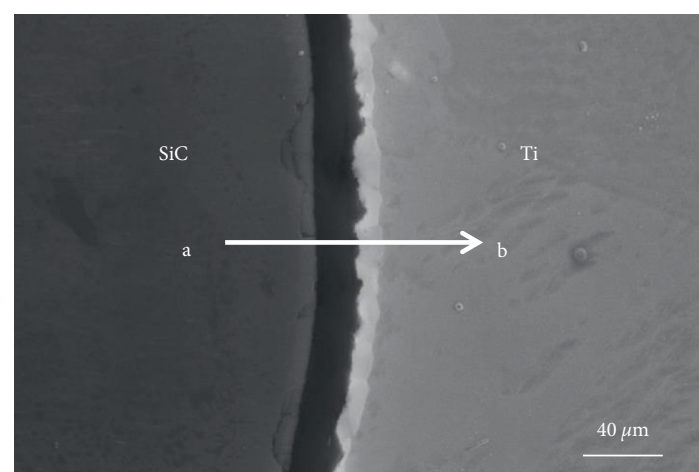

(c)

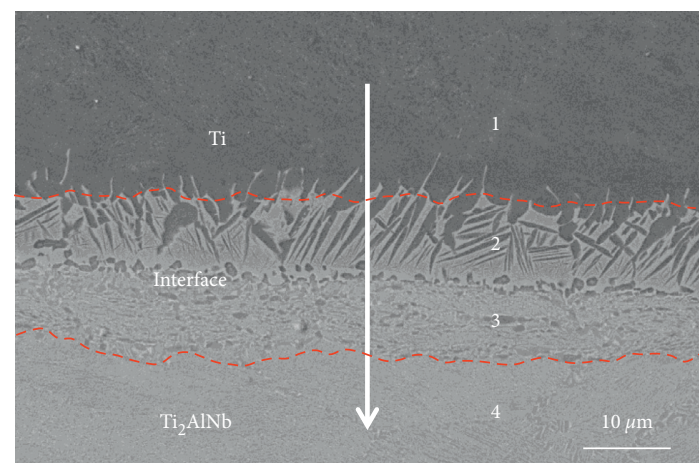

(e)

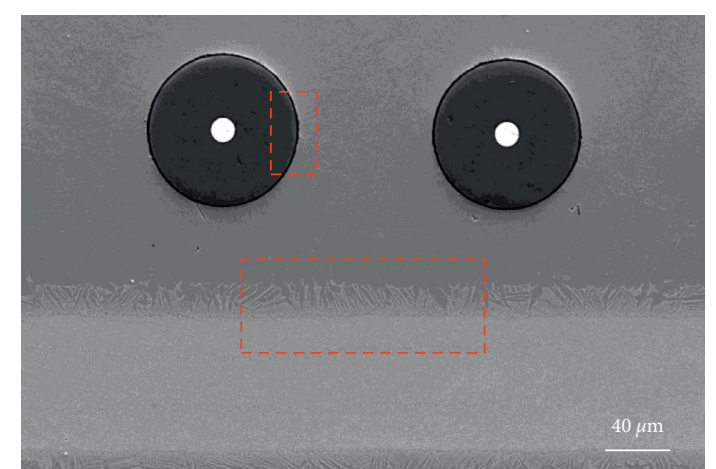

(b)

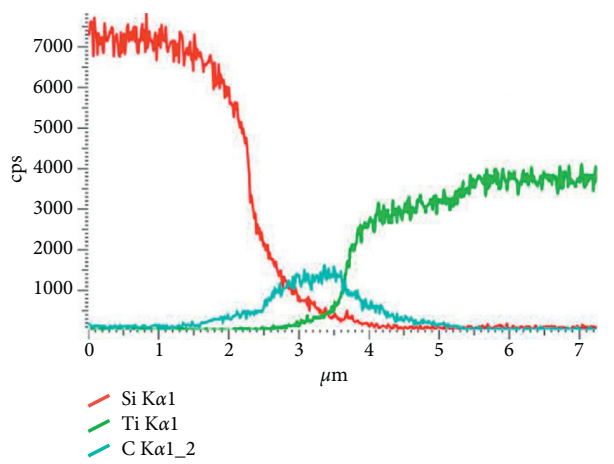

(d)

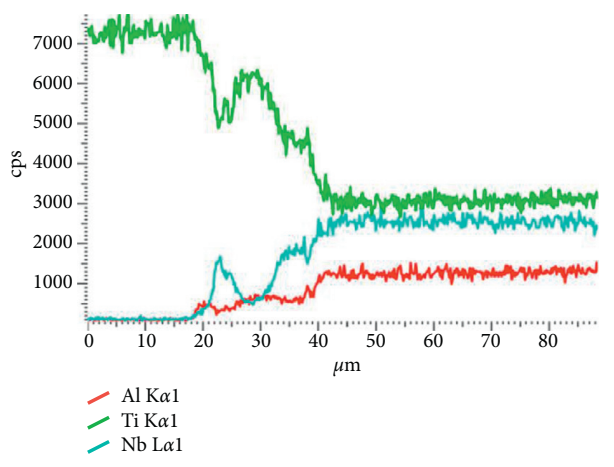

(f)

FigURE 5: Microstructure of the composite: (a) overall microstructure; (b) microstructure of one laminated component; (c) microstructure of the $\mathrm{SiC}_{f} / \mathrm{Ti}$ interface; (d) EDS line scanning over the $\mathrm{SiC}_{f} / \mathrm{Ti}$ interface; (e) microstructure of the $\mathrm{Ti} / \mathrm{Ti}_{2} \mathrm{AlNb}$ interface; (f) EDS line scanning over the $\mathrm{Ti} / \mathrm{Ti}_{2} \mathrm{AlNb}$ interface.

the $\mathrm{Ti} / \mathrm{Ti}_{2} \mathrm{AlNb}$ interface, with the results shown in Figure 5(f). It can be seen that in the direction from ductile metal $\mathrm{Ti}$ matrix to intermetallic compound $\mathrm{Ti}_{2} \mathrm{AlNb}$ (i.e., from Region 1 to Region 4), the Ti content shows a stepped decreasing trend but is maintained at a certain value at last. This is because during the hot working of the composite, the Ti element gradually spreads from Region 1 , where it shows a higher content, to Region 4, where it shows a lower content and finally ends. In this process, its microstructures are formed and distributed discretely in an inhomogeneous manner in interfacial transition Regions 2 and 3.

However, $\mathrm{Al}$ and $\mathrm{Nb}$ elements are distributed in a reverse trend of $\mathrm{Ti}$. In the direction of this research state, the contents of $\mathrm{Al}$ and $\mathrm{Nb}$ increase gradually from zero to a uniform and stable value. The specific analysis shows that there are no $\mathrm{Al}$ and $\mathrm{Nb}$ elements in the ductile metal $\mathrm{Ti}$ matrix (i.e., Region 1). Besides, during the hot working of the composite, these two elements, which are $\alpha$ and $\beta$ stable elements of $\mathrm{Ti}$, respectively, gradually spread from Region 4 to Region 1. Therefore, the microstructures of $\alpha+\beta$ biphase are formed in Region 2 on the side of the ductile metal $\mathrm{Ti}$ layer; and the microstructures of rich B2 phase with "abundant $\mathrm{Nb}$ and insufficient $\mathrm{Al}$ " are formed in Region 3 on the side of the intermetallic $\mathrm{Ti}_{2} \mathrm{AlNb}$ layer [22-25].

3.2. Test on Tensile Properties of the Composite. The tensile stress-strain curve of the continuous $\mathrm{SiC}$ ceramic fiberreinforced titanium-based laminated composite is presented in Figure 6, which shows that this composite's stress 


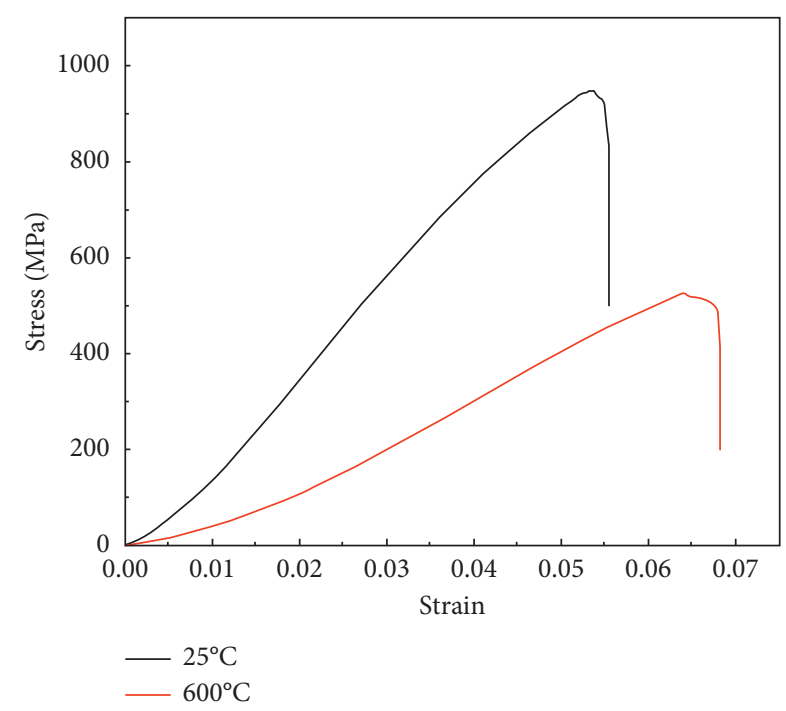

FIgURE 6: Curves for tensile mechanical properties of the composite.

increased with the strain at room $\left(25^{\circ} \mathrm{C}\right)$ and high $\left(600^{\circ} \mathrm{C}\right)$ temperatures in different magnitudes. That is, the latter increased more significantly than the former. This is because the composite matrix was relatively softened at high temperatures, which reduced its elasticity modulus. The composite's stress continued to increase with the strain at room temperature. When the latter increased to the value of 0.053 , the former reached its peak, 948.76 MPa. Then, with the continuous increase of the strain, the composite rapidly developed from the stage of elastic deformation to the stage of plastic deformation. Meanwhile, the brittle fiber fracture and matrix cracking occurred inside the composite, which changed its bearing structure and reduced its bearing capacity. There was a catastrophic failure in the composite when its strain increased to 0.056 .

In addition, when the composite's strain increased to 0.063 at high temperatures, its stress reached its peak, $526.62 \mathrm{MPa}$, which reduced by $44.4 \%$ compared with the value at room temperature. At this point, the composite entered the stage of plastic deformation. Then, as the strain increased continuously, the composite's bearing capacity gradually decreased and finally reduced to zero when the plastic strain became 0.068 . According to the above analysis, the composite's elasticity modulus and tensile strength at room temperature were higher than those at high temperatures, while its plastic ductility was lower than that at high temperatures.

Figure 7 presents the composite's tensile fracture, and the fracture's morphological structures at room and high temperatures are shown in Figures 7 (a) and $7(\mathrm{~d})$, respectively. It can be seen that, under both conditions, the composite showed "stepped" fracture characteristics, and, at the same time, the $\mathrm{SiC}$ ceramic fiber was pulled out. This indicated that the $\mathrm{SiC}$ ceramic fiber, as the reinforcement, was combined with the metal Ti matrix in a proper strength. In the loading process, the composite transferred the external load from the matrix to the fiber through the fiber/matrix interface to make the fiber bear the load. Then, when the load that kept increasing exceeded the longitudinal shear force at this interface, the $\mathrm{SiC}$ ceramic fiber was "pulled out and displaced" from the ductile metal Ti matrix in the direction of this load. Then, with the further increase of this external load, the fiber was broken longitudinally. Thus, the ductile metal $\mathrm{Ti}$ layer lost its bearing capacity [26-28].

When the composite was stretched at room temperature, the $\mathrm{SiC}$ ceramic fiber was obviously debonded from the metal Ti matrix, as shown in Figure 7(b). Meanwhile, some interfacial reaction products were attached to the residual $\mathrm{C}$ coating on the fiber. At this point, the fiber showed a typical brittle fracture, and the ductile metal $\mathrm{Ti}$ layer showed a typical ductile fracture, with obvious dimples and tear ridges. It can be seen from Figure 7(c) that there were a large number of lamellar structures with "river patterns" in the intermetallic $\mathrm{Ti}_{2} \mathrm{AlNb}$ layer, showing obvious brittle fracture characteristics. According to Figure 7(e), when the composite was subjected to an external load at the high-temperature tensile state, the $\mathrm{SiC}$ ceramic fiber was broken and pulled out in an axial direction along the fiber body, with the pull-out distance longer than that in the loaded state at room temperature. This is because the ductile metal Ti matrix was softened significantly at $600^{\circ} \mathrm{C}$ and interlayer interface separation occurred, which further weakened the interface bonding between the reinforcement fiber and the Ti matrix of the ductile layer. Thus, the $\mathrm{SiC}$ ceramic fiber entered a free state and could not bear any external load, which reduced the composite's mechanical bearing capacity. Meanwhile, when the composite was loaded at high temperature, a large number of dimples and tear ridges were formed in the $\mathrm{Ti}$ matrix of the ductile layer. As shown in Figure 7(f), due to the softening effect on the matrix at high temperature, the deformation of the composite's $\mathrm{Ti}_{2} \mathrm{AlNb}$ layer under the external tensile load gradually changed from a single brittle type at room temperature to a ductile-brittle type, accompanied by a small number of dimples and tear ridges. Besides, the shape and size of the lamellar structures with "river patterns" were reduced, which improved the composite's plastic deformation capacity.

\subsection{Test on Bending Properties of the Composite. Figure 8} depicts the load-displacement curves of the continuous $\mathrm{SiC}$ ceramic fiber-reinforced $\mathrm{Ti} / \mathrm{Ti}_{2} \mathrm{AlNb}$ laminated composite and the $\mathrm{Ti} / \mathrm{Ti}_{2} \mathrm{AlNb}$ laminated composite without $\mathrm{SiC}$ ceramic fiber as the reinforcement in the three-point bending test. For the former, as the pressure head was displaced increasingly, the load borne by the composite increased linearly. At this point, the composite's bending modulus was 68.11 GPa. When the external load reached $393.44 \mathrm{~N}$, the composite's bearing capacity relatively reduced. However, as the pressure head continued to move down, this capacity showed a rising trend again. This is because the composite lost part of its bearing capacity when some $\mathrm{SiC}$ ceramic fibers were broken under the external load of 393.44 N. Moreover, when the pressure head had a displacement of $2.03 \mathrm{~mm}$, this capacity reached its maximum value, $401.65 \mathrm{~N}$, and the bending strength was $1506.21 \mathrm{MPa}$. Then, the bearing capacity gradually weakened and finally reduced to zero when the pressure head was displaced by $4.45 \mathrm{~mm}$. 

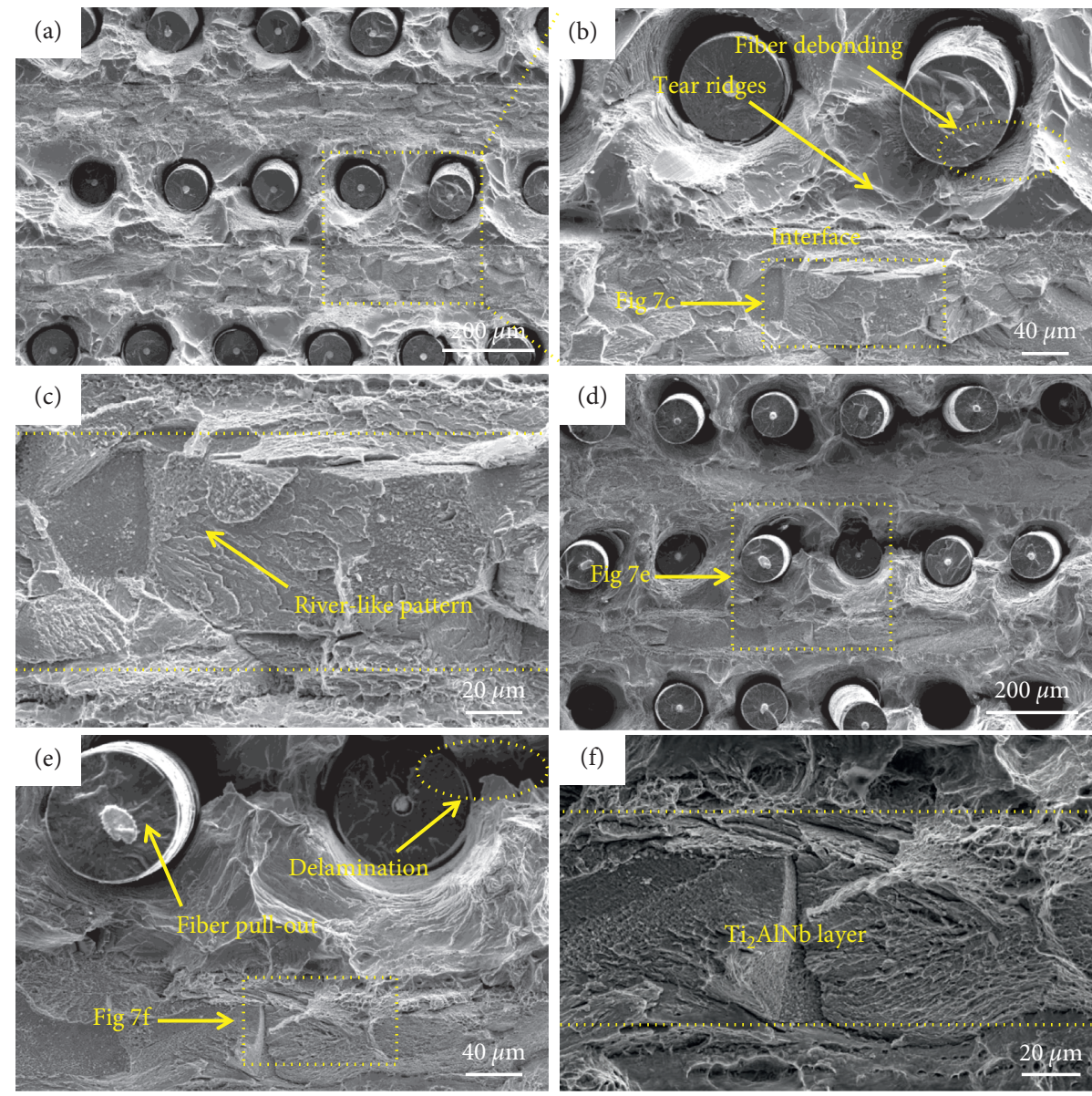

Figure 7: Tensile fracture of the composite: $(\mathrm{a}-\mathrm{c})$ at room temperature and $(\mathrm{d}-\mathrm{f})$ at high temperatures.

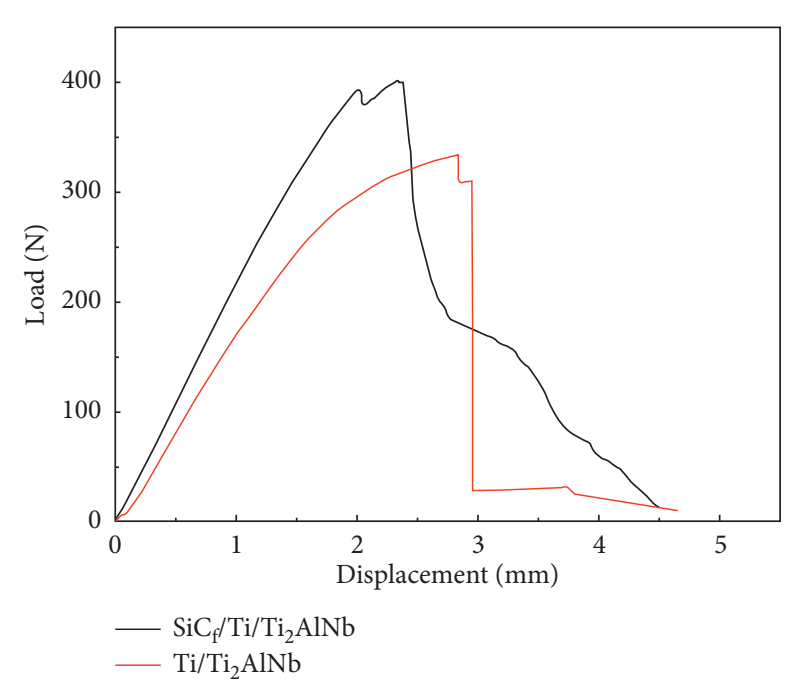

FIGURE 8: Load-displacement curves of the composite in the threepoint bending test.

In contrast, as the external load increased, the $\mathrm{Ti} / \mathrm{Ti}_{2} \mathrm{AlNb}$ laminated composite without $\mathrm{SiC}$ ceramic fiber as the reinforcement entered the stage of elastic deformation, showing a bending modulus of $58.76 \mathrm{GPa}$, which was much lower than that of the continuous $\mathrm{SiC}$ ceramic fiber- reinforced $\mathrm{Ti} / \mathrm{Ti}_{2} \mathrm{AlNb}$ laminated composite. Then, when the pressure head was displaced by $1.78 \mathrm{~mm}$, the composite entered the stage of plastic deformation. At this point, as the pressure head was displaced increasingly, the external load borne by the composite increased slowly. When the pressure head had a displacement of $2.83 \mathrm{~mm}$, the composite's bearing capacity reached its peak, $338.61 \mathrm{~N}$, and the bending strength was $1269.82 \mathrm{MPa}$. Then, this capacity plummeted to the extent of total failure as the pressure head was displaced continuously.

Figure 9 presents the composite's three-point bending fracture. According to Figure 9(a), the fracture morphology showed a "stepped" distribution. The intermetallic $\mathrm{Ti}_{2} \mathrm{AlNb}$ layer and SiC ceramic fiber-reinforced ductile metal Ti layer presented different fracture modes, which may be caused by the heterostructure characteristics of the composite's components. It was further found that the ductile metal $\mathrm{Ti}$ was laminated on both sides of some $\mathrm{SiC}$ ceramic fibers, which indicated that these fibers were sensitive to the external bending load when the composite was subjected to this load. In addition, as the SiC ceramic fiber was bent, the loading force was transferred to the metal $\mathrm{Ti}$ matrix to separate the $\mathrm{Ti}$ adjacent to some fibers.

As shown in Figures 9(b) and 9(c), the $\mathrm{SiC}$ ceramic fiber and metal Ti matrix were debonded, and the most interfacial reaction products caused by metallurgical bonding were left 


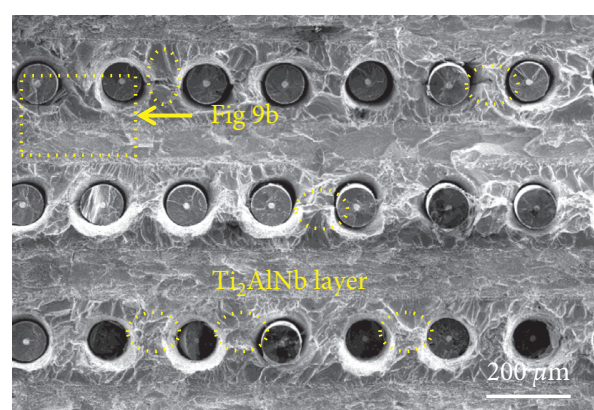

(a)

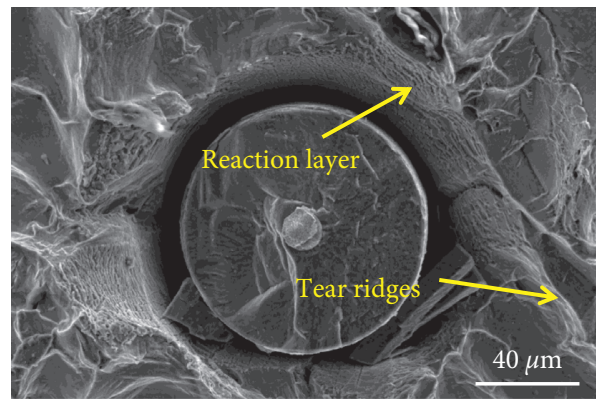

(c)

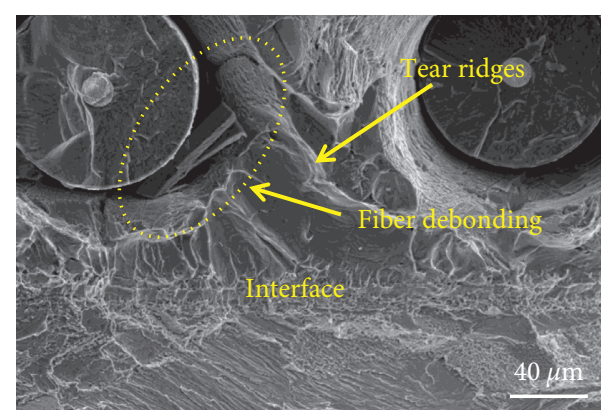

(b)

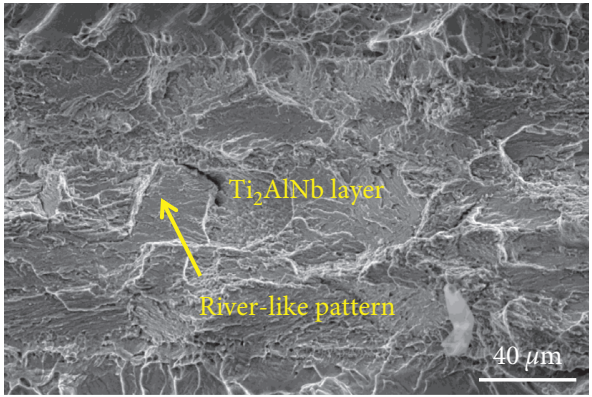

(d)

FIGURE 9: Three-point bending fracture of the composite: (a) macrofracture; (b) fracture of one laminated component; (c) fracture in the $\mathrm{SiC}_{f} / \mathrm{Ti}$ interface, and (d) fracture in the $\mathrm{Ti}_{2} \mathrm{AlNb}$ layer.

on the matrix and the outer side of the residual $\mathrm{C}$ coating on the fiber. Besides, the $\mathrm{SiC}$ ceramic fiber showed typical brittle fracture characteristics; and the ductile metal $\mathrm{Ti}$ matrix showed typical ductile fracture characteristics, with a large number of tear ridges and dimples. Figure 9(d) presents the fracture morphology in the intermetallic $\mathrm{Ti}_{2} \mathrm{AlNb}$ layer. It can be seen that there were a lot of lamellar structures with "river patterns" on the fracture of this layer, showing a typical brittle fracture.

Figure 10 shows the growth of in-situ three-point bending cracks of the hybrid laminated composite. Figures $10(\mathrm{a})-10(\mathrm{~h})$ describe the process of crack generation, crack growth, and final failure of the composite during the three-point bending process. As shown in Figure 10(a), the load head is located at the lower part. During the test, the upper and lower parts of the specimen of composite bear tensile stress and compressive stress loads, respectively. With a gradual increase of external load, the brittle fracture of the $\mathrm{SiC}$ ceramic fiber on the upper part of the composite occurs in the fiber direction first, as shown in Figure 10(b). In Figure $10(\mathrm{c})$, as the external load continues to increase, cracks are gradually generated and extend downward at the $\mathrm{Ti}_{2} \mathrm{AlNb}$ layer on the upper part of the composite. In Figure 10(d), the crack on the upper part of the composite passes through the $\mathrm{Ti}_{2} \mathrm{AlNb}$ layer and the ductile $\mathrm{Ti}$ layer. The crack tip meets the $\mathrm{SiC}$ ceramic fiber, which hinders the crack growth and deflects the crack. At the same time, the $\mathrm{Ti}_{2}$ AlNb layer in the middle of the composite is subjected to tensile stress load and cracks. When the external load is further increased, the crack on the top of the composite deflects and passes through the SiC fiber and then merges with the cracks in the $\mathrm{Ti}_{2} \mathrm{AlNb}$ layer at the lower part of the composite (as shown in Figures 10(e) and 10(f)). At this moment, new microcracks gradually develop in the SiC fiber layer and $\mathrm{Ti}_{2} \mathrm{AlNb}$ layer at the lower part of the composite. In Figures $10(\mathrm{~g})$ and $10(\mathrm{~h})$, the upper and lower cracks in the specimen of the composite intersect each other. Therefore, failure of composite occurs when it loses its bearing capacity.

Furthermore, it can be seen from Figure 10(h) that when the $\mathrm{SiC}$ ceramic fiber reinforced $\mathrm{Ti} / \mathrm{Ti}_{2} \mathrm{AlNb}$ hybrid laminated composite is subjected to bending load, the crack does not spread along a straight line but spreads into the specimen in a dendritic manner, and finally the tip of crack extends from the upper part of the specimen to the lower part of the specimen along the "broken line," because the $\mathrm{SiC}$ ceramic fiber bridges the cracks that bypass it and spread forward.

Figure 11 illustrates the composite's failure mechanism under the three-point bending load. As the pressure head moved down, the composite entered the initial stage of three-point bending loading. At this point, the composite's structural components on its lower part were subjected to the tensile stress, while those on the upper part were subjected to the compressive stress, as shown in Figure 11(a). In Figure 11(b), as the pressure head moved down, the composite bore a larger external load, which increased the tensile stress on the lower part. Then, when this stress was higher than the $\mathrm{SiC}$ ceramic fiber's tensile strength, the fiber was broken internally.

As the pressure head kept moving down, this tensile stress continued to increase, resulting in microcracks on the composite's lower surface, as shown in Figure 11(c). In the meantime, the microcracks on the outer side of the composite, as the initial source of crack trajectory, propagated inwards, which occurred along with the absorption of load 


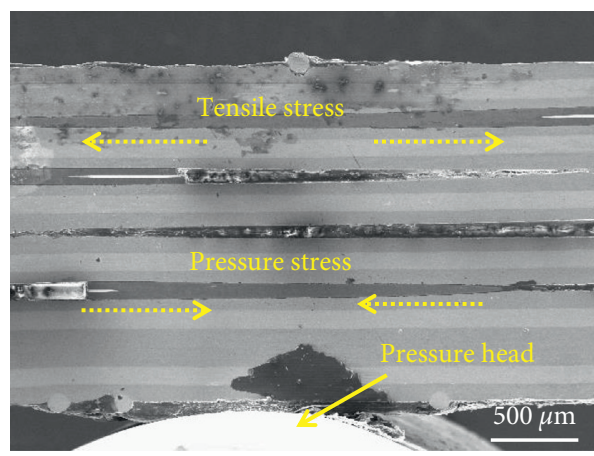

(a)

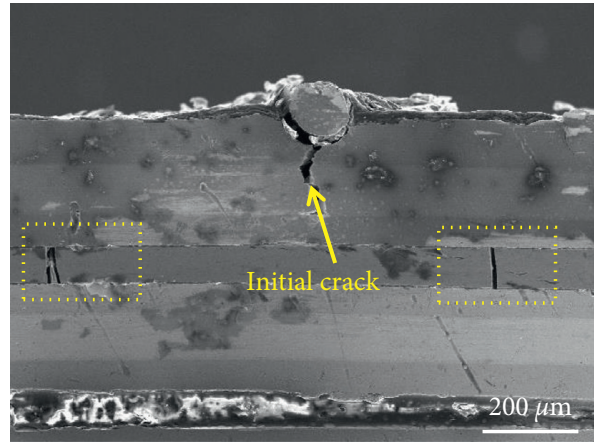

(c)

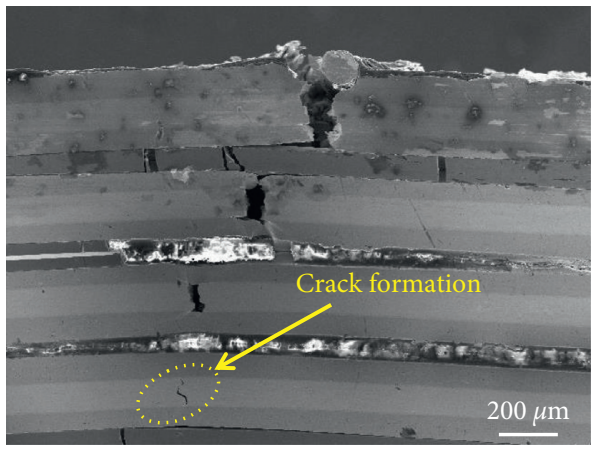

(e)

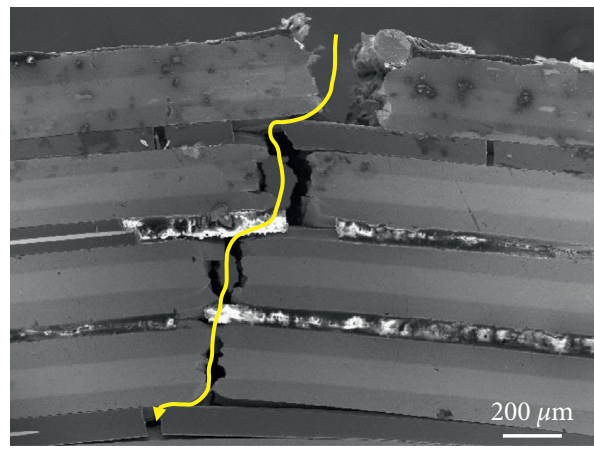

(g)

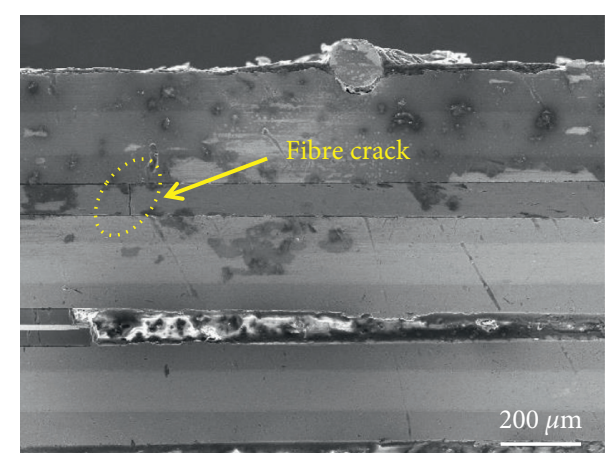

(b)

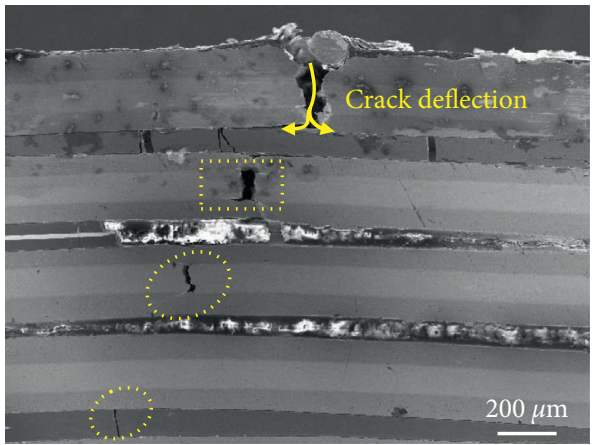

(d)

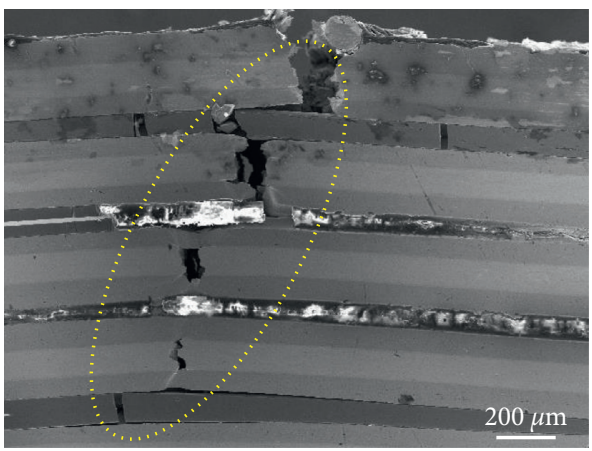

(f)

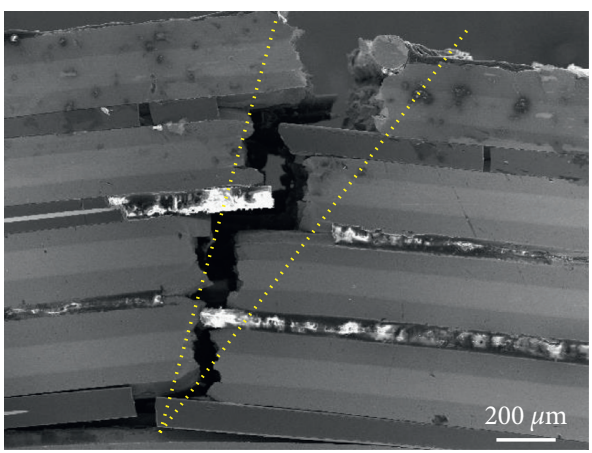

(h)

FIGURE 10: Scanning electron microscopy (SEM) micrographs of in-situ three-point bending test of the composite. (a) Initial state of loading; (b) initial brittle cracking of fiber; ( $\mathrm{c}-\mathrm{g}$ ) generation and spreading of cracks in the composite; (h) failure state of the composite.

energy. In addition, in this process, there was a crackbridging phenomenon caused by heterostructure characteristics of the composite's components [29-31], as shown in Figures 11(d) and 11(e). As the pressure head was displaced continuously, these cracks expanded from the lower part towards the upper part, forming a path of winding propagation. Thus, the composite lost its bearing capacity completely, as shown in Figure 11(f). 


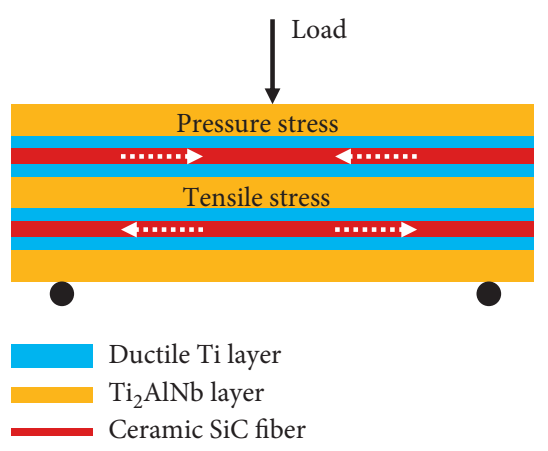

(a)

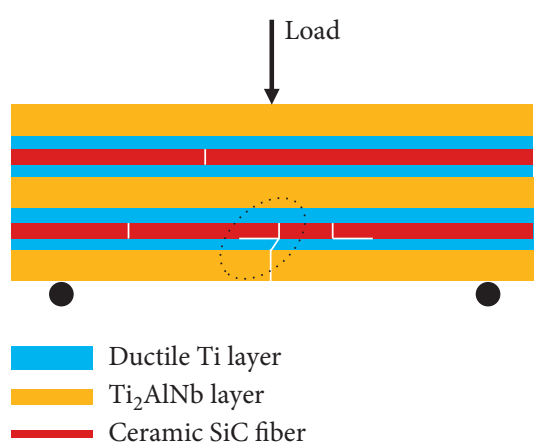

(d)

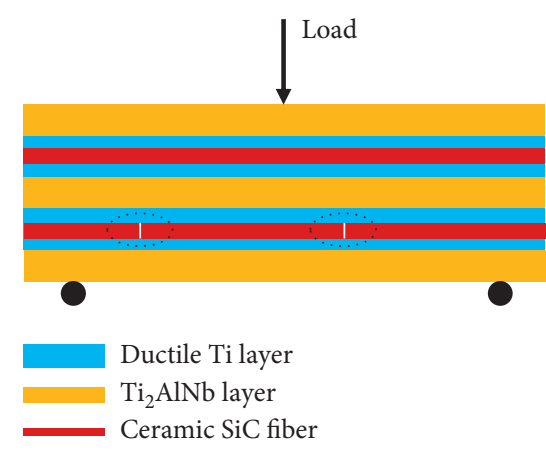

(b)

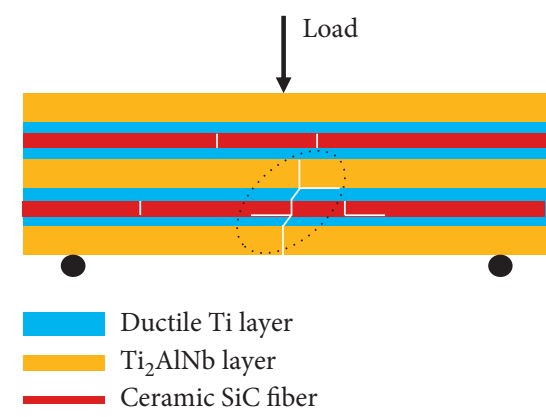

(e)

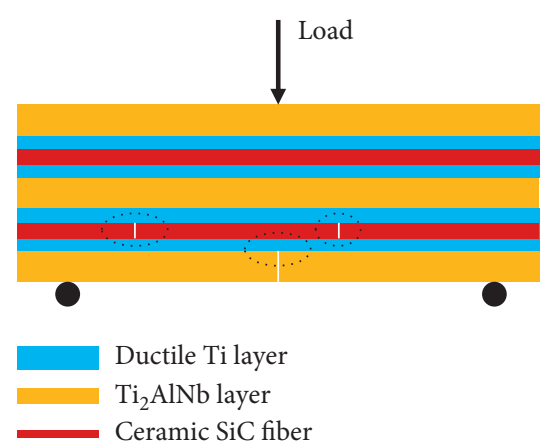

(c)

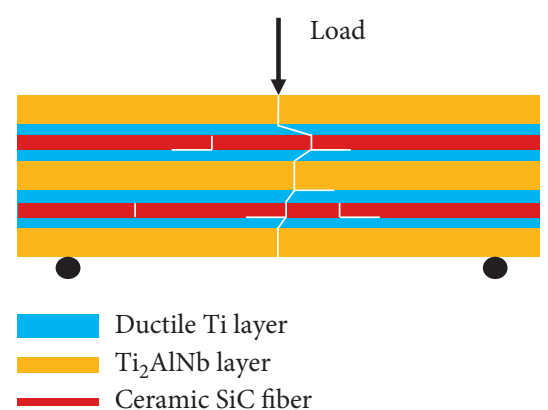

(f)

FiguRE 11: Failure mechanism schematic diagrams for the three-point bending of the composite: (a) initial loading stage; (b) stage of brittle fiber fracture under the load; (c) stage for the formation of crack sources on the surface; (d) initial stage of crack propagation; (e) cross-layer stage of crack propagation; and (f) failure stage of crack propagation.

\section{Conclusions}

(1) The continuous $\mathrm{SiC}$ ceramic fiber, ductile metal $\mathrm{Ti}$ foil, and intermetallic $\mathrm{Ti}_{2} \mathrm{AlNb}$ foil were selected as raw materials to prepare the continuous $\mathrm{SiC}$ ceramic fiber-reinforced titanium-based laminated composite by vacuum hot pressing and fiber braiding technologies. This composite's structural components were metallurgically bonded well. Among them, the SiC ceramic fiber was equidistantly distributed in the ductile metal Ti matrix. In the prepared state, the composite's phase was mainly composed of $\alpha$-Ti, $\beta$-Ti, $\mathrm{SiC}, \mathrm{TiC}, \mathrm{O}$ phase, and $\mathrm{B} 2$ phase.

(2) The composite's ultimate tensile strengths perpendicularly along the $\mathrm{SiC}$ ceramic fiber were 948.76 MPa and $526.62 \mathrm{MPa}$ at room temperature and $600^{\circ} \mathrm{C}$, respectively; and the corresponding tensile elongations were 0.056 and 0.068 , respectively. Meanwhile, its tensile fracture showed a "stepped" distribution. When this composite was subjected to a load, the SiC ceramic fiber would be debonded from the ductile metal Ti matrix, and some fibers would be "pulled out." Besides, the intermetallic $\mathrm{Ti}_{2} \mathrm{AlNb}$ layer showed obvious brittle fracture characteristics.

(3) The three-point bending test was carried out on the continuous $\mathrm{SiC}$ ceramic fiber-reinforced $\mathrm{Ti} / \mathrm{Ti}_{2} \mathrm{AlNb}$ laminated composite and the $\mathrm{Ti} / \mathrm{Ti}_{2} \mathrm{AlNb}$ laminated composite without $\mathrm{SiC}$ ceramic fiber as the reinforcement. Thereinto, their bending strengths were $1506.21 \mathrm{MPa}$ and $1269.82 \mathrm{MPa}$, respectively; and their bending moduli were $68.11 \mathrm{GPa}$ and $58.76 \mathrm{GPa}$, respectively. It can be seen that after the $\mathrm{SiC}$ ceramic fiber was added, the composite's bending strength and modulus were improved significantly. Meanwhile, the composite's mode of crack propagation and failure mechanism were analyzed under the three-point bending load.

\section{Data Availability}

The data used to support the findings of this study are included in the article. Further dataset or information is available from the corresponding author upon request.

\section{Conflicts of Interest}

The authors declare that they have no conflicts of interest.

\section{References}

[1] J. H. Lou, Y. Q. Yang, Q. Sun, J. Li, and X. Luo, "Study on longitudinal tensile properties of $\mathrm{SiCf} / \mathrm{Ti}-6 \mathrm{Al}-4 \mathrm{~V}$ composites with different interfacial shear strength," Materials Science and Engineering, vol. 529, no. 25, pp. 88-93, 2011.

[2] S. Guo and Y. Kagawa, "Characterization of interface sliding damage in SiC fiber-reinforced Ti-15-3 matrix composite by cyclic fatigue," Acta Materialia, vol. 45, no. 6, pp. 2257-2270, 1997. 
[3] X. H. Lü, Y. Q. Yang, X. Luo, B. Huang, Y. C. Liü, and Y. Chen, "Experimental and theoretical study of diffusion bonding in fabricating Ti matrix composite," Materials Science and Engineering A, vol. 458, p. 202, 2007.

[4] G. H. Feng, Y. Q. Yang, X. Luo, J. Li, B. Huang, and Y. Chen, "Fatigue properties and fracture analysis of a $\mathrm{SiC}$ fiberreinforced titanium matrix composite," Composites Part B: Engineering, vol. 68, pp. 336-342, 2015.

[5] S. Zhang, M. Wang, M. Wen, M. Wu, Q. Wang, and $\mathrm{H}$. Huang, "Interfacial reactions and matrix microstructure evolution in SiCf/Ti composites dominated by primary structure of Ti matrix," Ceramics International, vol. 45, no. 14, pp. 17767-17774, 2019.

[6] Y. Q. Yang, H. J. Dudek, and J. Kumpfert, "Interfacial reaction and stability of SCS-6 SiC/Ti-25Al-10NB-3V-1MO composites," Materials Science and Engineering, vol. 246, no. 1-2, pp. 213-220, 1998.

[7] Q. Sun, X. Luo, Y. Q. Yang, G. H. Feng, G. M. Zhao, and B. Huang, "A review on the research progress of push-out method in testing interfacial properties of $\mathrm{SiC}$ fiber-reinforced titanium matrix composites," Composite Interfaces, vol. 22, no. 5, pp. 367-386, 2015.

[8] W. Zhang, Y. Q. Yang, G. M. Zhao et al., "Investigation of interfacial reaction in SiC fiber reinforced Ti-43Al-9V composites," Intermetallics, vol. 33, pp. 54-59, 2013.

[9] G. M. Zhao, Y. Q. Yang, W. Zhang, X. Luo, B. Huang, and Y. Chen, "Microstructure and grain growth of the matrix of $\mathrm{SiCf} / \mathrm{Ti}-6 \mathrm{Al}-4 \mathrm{~V}$ composites prepared by the consolidation of matrix-coated fibers in the $\beta$ phase field," Composites Part B: Engineering, vol. 52, pp. 155-163, 2013.

[10] H.-P. Chiu, S. M. Jeng, and J.-M. Yang, "Interface control and design for $\mathrm{SiC}$ fiber-reinforced titanium aluminide composites," Journal of Materials Research, vol. 8, no. 8, pp. 2040-2053, 1993.

[11] Y. C. Her, J.-M. Yang, and P. C. Wang, "Effect of fiber coating on the fatigue crack initiation and multiplication of unnotched SCS-6/Ti3Al composites," Materials Science and Engineering, vol. 259, no. 2, pp. 201-208, 1999.

[12] X. Luo, C. Li, Y.-q. Yang et al., "Microstructure and interface thermal stability of $\mathrm{C} / \mathrm{Mo}$ double-coated $\mathrm{SiC}$ fiber reinforced $\gamma$-TiAl matrix composites," Transactions of Nonferrous Metals Society of China, vol. 26, no. 5, pp. 1317-1325, 2016.

[13] T. T. Ai, Q. F. Niu, Z. F. Deng et al., "Nature-inspired nacrelike $\mathrm{Ti} 6 \mathrm{Al} 4 \mathrm{~V}-\left(\mathrm{Ti}_{2} \mathrm{AlC} / \mathrm{TiAl}\right)$ laminate composites combining appropriate strength and toughness with synergy effects," Intermetallics, vol. 121, Article ID 106774, 2020.

[14] K. Zhu, Y.-J. Xu, T. Jing, and H.-L. Hou, "Fracture behavior of a composite composed by Ti-aluminide multi-layered and continuous-SiCf-reinforced Ti-matrix," Rare Metals, vol. 36, no. 12, pp. 925-933, 2017.

[15] W. Sun, H. Fan, F. You, F. Kong, X. Wang, and Y. Chen, "Prediction of interfacial phase formation and mechanical properties of Ti6Al4V-Ti43Al9V laminate composites," Materials Science and Engineering, vol. 782, Article ID 139173, 2020.

[16] Y.-J. Guo, Z.-Q. Shi, Y.-K. Xu, and G.-J. Qiao, “Correlation between microstructure and tensile behavior of metal-intermetallic laminate compound with different initial $\mathrm{Ni}$ foil thickness," Rare Metals, vol. 33, no. 2, pp. 196-202, 2014.

[17] Z.-Z. Shen, J.-P. Lin, Y.-F. Liang, L.-Q. Zhang, and G.-J. Hao, "Reaction behaviors occurring in Ti/Al foil metallurgy," Rare Metals, vol. 35, no. 1, pp. 100-105, 2015.

[18] W. Sun, F. You, F. Kong, X. Wang, and Y. Chen, "Enhanced tensile strength and fracture toughness of a Ti-TiAl metal- intermetallic laminate (MIL) composite," Intermetallics, vol. 118, Article ID 106684, 2020.

[19] S. Lyu, Y. Sun, G. Li, W. Xiao, and C. Ma, "Effect of layer sequence on the mechanical properties of Ti/TiAl laminates," Materials \& Design, vol. 143, pp. 160-168, 2018.

[20] Y. C. Fu, N. L. Shi, D. Z. Zhang, and R. Yang, "Effect of C coating on the interfacial microstructure and properties of $\mathrm{SiC}$ fiber-reinforced Ti matrix composites," Materials Science and Engineering, vol. 426, no. 1-2, pp. 278-282, 2006.

[21] B. Huang, Y. Q. Yang, Y. W. Mei, X. Luo, J. K. Li, and Y. Chen, "Studies on interface of $\mathrm{SiC}_{f} / \mathrm{Ti} 55$ composite," Rare Metal Materials and Engineering, vol. 38, no. 10, p. 1703, 2009.

[22] L. J. Tan, Z. K. Yao, T. Wang, and H. Z. Guo, "Effect of postweld heat treatment on microstructure and properties of electron beam welded joint of Ti2AlNb/TC11," Materials Science and Technology, vol. 27, no. 8, pp. 1315-1320, 2011.

[23] S. Wang, Y. Chen, and L. Li, "Effect of beam deviation on electron beam welded Ti-22Al-25Nb/TC4 dissimilar alloys," Welding in the World, vol. 64, no. 4, pp. 661-670, 2020.

[24] Z. L. Lei, Z. J. Dong, Y. B. Chen, L. Huang, and R. C. Zhu, "Microstructure and mechanical properties of laser welded Ti22Al-27Nb/TC4 dissimilar alloys," Materials Science and Engineering, vol. 559, pp. 909-916, 2013.

[25] D. Li, S. Hu, J. Shen, H. Zhang, and X. Bu, "Microstructure and mechanical properties of laser-welded joints of Ti-22Al$25 \mathrm{Nb}$ /TA15 dissimilar titanium alloys," Journal of Materials Engineering and Performance, vol. 25, no. 5, pp. 1880-1888, 2016.

[26] K. Naseem, Y. Yang, X. Luo, B. Huang, and G. Feng, "SEM in situ study on the mechanical behaviour of SiCf/Ti composite subjected to axial tensile load," Materials Science and Engineering, vol. 528, no. 13-14, pp. 4507-4515, 2011.

[27] C. Lin, Y. Han, C. Guo et al., "Synthesis and mechanical properties of novel $\mathrm{Ti}$-(SiCf/Al3Ti) ceramic-fiber-reinforced metal-intermetallic-laminated (CFR-MIL) composites," Journal of Alloys and Compounds, vol. 722, no. 25, pp. 427-437, 2017.

[28] Z. Kai, W. Yu, A. Yann, and J. Tao, "Synthesis, microstructure and mechanical properties of a bio-inspired Ti-intermetallic multi-layered/SiC $\mathrm{f}_{\mathrm{f}}$-reinforced Ti-matrix hybrid composite," Journal of Materials Science, vol. 51, no. 18, p. 8747, 2016.

[29] W. Yu, K. Zhu, Y. Aman, Z. Guo, and S. Xiong, "Bio-inspired design of SiCf-reinforced multi-layered Ti-intermetallic composite," Materials \& Design, vol. 101, no. 7, pp. 102-108, 2016.

[30] B. X. Liu, L. J. Huang, B. Kaveendran et al., "Tensile and bending behaviors and characteristics of laminated Ti-(TiBw/ Ti) composites with different interface status," Composites Part B: Engineering, vol. 108, pp. 377-385, 2017.

[31] K. S. Vecchio and F. Jiang, "Fracture toughness of ceramicfiber-reinforced metallic-intermetallic-laminate (CFR-MIL) composites," Materials Science and Engineering, vol. 649, pp. 407-416, 2016. 